\title{
IGF1R Negative
}

National Cancer Institute

\section{Source}

National Cancer Institute. IGF1R Negative. NCI Thesaurus. Code C150644.

An indication that expression of IGF1R has not been detected in a sample. 